\title{
PERANCANGAN DESTINATION BRANDING DESA WISATA KETENGER KABUPATEN BANYUMAS UNTUK MENDUKUNG PROGRAM DIGITAL DESTINATION
}

\author{
Monica Revias Purwa Kusuma ${ }^{1}$, Elianna Gerda Pertiwi ${ }^{2}$ \\ 1,2Program Studi Desain Komunikasi Visual, Fakultas Teknologi Industri \& Informatika, Institut Teknologi \\ Telkom Purwokerto, Jl. D.I Panjaitan No.128 Purwokerto \\ email: ${ }^{1}$ revias@ittelkom-pwt.ac.id, ${ }^{2}$ elianna@ittelkom-pwt.ac.id
}

\begin{abstract}
Abstrak: Desa Wisata Ketenger di Kabupaten Banyumas memiliki potensi alam yang sangat indah, akan tetapi tidak memiliki branding ataupun promosi yang baik. Image Desa Wisata Ketenger perlu diperbaiki dengan melakukan perancangan destinasion branding agar dapat merubah persepsi target audience dan menjadikannya sebagai alternatif tujuan pariwisata di Kabupaten Banyumas. Metode yang digunakan pada penelitian ini adalah observasi, wawancara, dokumentasi, dan studi literatur. Tujuan penelitian ini adalah untuk meningkatkan daya tarik wisatawan agar datang dan berkunjung ke Desa Wisata Ketenger sekaligus mendukung program digital destination yang dicanangkan oleh Kemenpar. Hasil dari penelitian ini adalah perancangan identitas baru Desa Wisata Ketenger yang berupa logo, spanduk, billboard, brosur, karcis, kaos, gapura, sign system terpadu, spot fotogenik, dan Instagram. Kesimpulan dari penelitian ini bahwa perancangan destination branding suatu daerah merupakan salah satu hal yang perlu dilakukan untuk membantu terlaksananya program pariwisata digital destination yang dibuat oleh pemerintah.
\end{abstract}

Kata kunci: pariwisata, branding destinasi wisata, destinasi digital, Desa Wisata Ketenger

\begin{abstract}
Ketenger Tourism Village in Kabupaten Banyumas has very beautiful natural potential, but does not have a good branding or promotion. Image Kete nger Tourism Village needs to be improved by designing destination branding in order to change the perception of the target audience and make it an alternative tourism destination in the Banyumas regency. The method used in this research is observation, interviews, documentation, and literature studies. The purpose of this research is to increase the attractiveness of tourists to come and visit Ketenger Tourism Village while supporting the digital destination program launched by the Ministry of Tourism. The results of this study are the design of the new identity of Ketenger Tourism Village in the form of logos, banners, billboards, brochures, tickets, shirts, arches, integrated sign systems, photogenic spots, and Instagram. The conclusion of this study is that the design of destination branding in an area is one of the things that needs to be done to implement a digital destination tourism program made by the government.
\end{abstract}

Keywords: tourism, destination branding, digital destination, Ketenger Tourism Village 


\section{PENDAHULUAN}

Era digital mengakibatkan munculnya gaya hidup milenial yang serba menggunakan teknologi. Pemerintah melalui Kementerian Pariwisata mengemukakan bahwa tema unggulan untuk mendukung pariwisata di era digital ini salah satunya yaitu Digital Destination. Hal tersebut diungkapkan Menteri Pariwisata Arief Yahya pada event Pra Rakornas yang diadakan pada tanggal 2 April 2018. Diungkapkan pula bahwa digital destination atau destinasi digital adalah suatu destinasi yang dikreasikan oleh kaum milenial yang memiliki spot fotogenik agar bisa diviralkan melalui internet ataupun media sosial. Salah satu daya tarik wisata yang sedang dikembangkan oleh pemerintah adalah dibentuknya desa wisata potensial pada setiap daerah di tanah air. Menteri pariwisata bekerjasama dengan Menteri Koperasi dan UMKM beserta Menteri Desa Pembangunan Daerah Tertinggal dan Transmigrasi (DPDTT) bersinergi dalam pengembangan desa wisata di Indonesia.

Salah satu desa wisata yang berpotensi untuk dikembangkan adalah Desa Wisata Ketenger yang terletak di Kabupaten Banyumas. Prafitri (2016) menjelaskan bahwa Desa Wisata Ketenger terletak di Kecamatan Baturraden, Kabupaten Banyumas dan memiliki tiga dusun yaitu Dusun Karangmule, Dusun Ketenger, serta Dusun Kalipagu. Potensi wisata yang ada pada Desa Wisata Ketenger berupa wisata alam yaitu banyaknya air terjun yang sering disebut sebagai curug. Wisata alam yang ada di Desa Wisata Ketenger antara lain yaitu: Curug Pengantin, Curug Gedhe, Curug Celiling, Curug Bayan, Curug Jenggala, Curug Tempuhan, Curug Kembar, Curug Brajawingin, Curug Gumeng, Curug Petir, Dam Jepang, Wisata Kebun Anggrek Sekar Gumilang, dan PLTA. Walaupun sudah lama dicanangkan sebagai desa wisata, namun gaung desa wisata ini jarang terdengar karena keterbatasan dalam hal promosi dan fasilitas pendukung pariwisata yang sangat terbatas. Beberapa material promosi dan sign system memang terlihat dari awal pengunjung masuk ke Desa Wisata tersebut, tetapi sangat minim bahkan 
beberapa sudah usang dan rusak. Melihat dari permasalahan tersebut, perlu diadakannya sebuah upaya yang lebih baik dan terintegrasi untuk memperkenalkan Desa Wisata Ketenger sebagai salah satu alternatif pariwisata di Kabupaten Banyumas melalui perancangan destination branding.

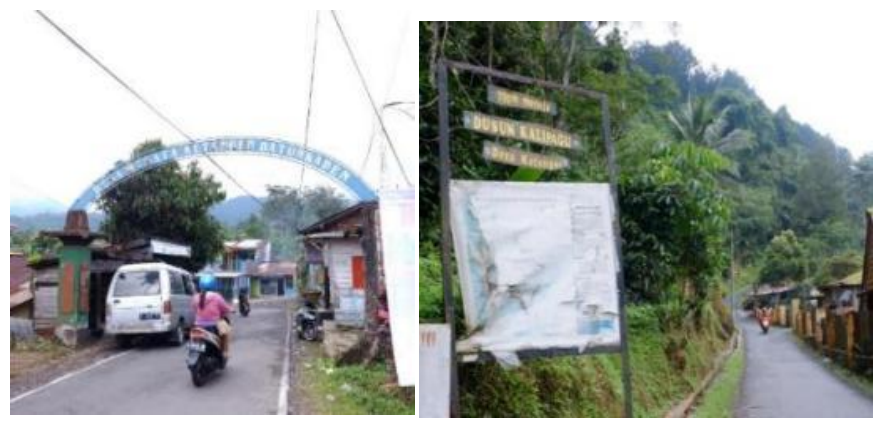

Gambar 1. Media promosi dan sign system di Desa Wisata Ketenger yang mulai rusak Sumber: Kusuma, 2018

Dalam perancangan destination branding Desa Wisata Ketenger ada hal yang paling penting untuk dibentuk terlebih dahulu yaitu suatu brand (merek). Freddy Rangkuti (2009:14) menjelaskan bahwa brand merupakan suatu nama atau simbol tententu yang diciptakan untuk membuat perbedaan suatu produk dengan yang lainnya. Perancangan suatu brand umumnya hanya dibuat untuk memperkenalkan suatu produk atau jasa, namun di era sekarang ini brand sudah banyak pula diterapkan di sektor pariwisata. Hal tersebut sering disebut sebagai destination branding, karena brand yang akan di rancang memiliki suatu tujuan agar destinasi wisata di suatu tempat menjadi lebih dikenal oleh masyarakat. Destination Branding mengacu pada karakteristik tempat yang menarik untuk dikunjungi dan memberikan suatu perasaan tertentu yang meninggalkan kesan mendalam dan melibatkan hubungan emosional dengan target audience-nya (Anholt, 2009:102).

Baker and Cameron (2008:79-97) mengumpulkan faktor-faktor penting yang harus dilakukan pada destination branding dari banyak literatur baik secara 
akademik maupun dari para praktisi. Beberapa faktor tersebut terbagi menjadi beberapa step berbeda pada proses pemasaran tujuan wisata tersebut, yaitu : orientasi strategis, identitas dan citra sebuah destinasi, keterlibatan pemangku kepentingan, serta implementasi, pemantauan, dan tinjauan.

Pada perancangan Desa Wisata Ketenger ini lebih difokuskan pada proses yang menggarap pada bagian identitas dan citra sebuah destinasi karena secara khusus berhubungan dengan keilmuan Desain Komunikasi Visual. Desain Komunikasi Visual adalah ilmu yang memberi pelajaran tentang konsep komunikasi serta ungkapan daya kreatif yang diterapkan pada bermacam media komunikasi visual dengan mengolah elemen desain grafis seperti ilustrasi/gambar, huruf/tipografi, warna, komposisi,dan layout (Tinarbuko,2015:5). Ada beberapa poin penting dalam pembentukan identitas dan citra sebuah destinasi yang akan digunakan sebagai dasar perancangan destination branding Desa Wisata Ketenger yaitu kebutuhan untuk membuat identitas brand agar diakui, menentukan positioning, mengorganisasikan material promosi, serta membuat pengalaman baru bagi turis agar bisa merasakan keunikan suatu destinasi.

Sebelum merancang destination branding Desa Wisata Ketenger hal utama yang perlu dipahami terlebih dahulu yaitu apa saja yang akan dirancang untuk membentuk suatu identitas dan citra desa wisata tersebut. Aline Wheeler (2013:124-182) mengemukakan hal-hal yang bisa dirancang dalam pembentukan brand, beberapa contohnya adalah logo, warna, tipografi, advertising, signage, ataupun enviroment.

Dari latar belakang diatas maka dirumuskan suatu permasalahan yaitu bagaimana merancang destination branding Desa Wisata Ketenger dengan mediamedia yang informatif dan menarik?

Lingkup yang akan di bahas pada penelitian ini adalah perancangan destination branding Desa Wisata Ketenger terutama pada obyek-obyek wisata alam yang ada di dalamnya. Obyek wisata yang dipilih adalah yang sudah memiliki 
akses yang baik untuk wisatawan yaitu Curug Bayan, Curug Gede, Curug Kembar, Curug Jenggala, Wisata Kebun Anggrek Sekar Gumilang, dan Wisata Dam Jepang.

\section{METODE PENELITIAN}

Adapun fokus dari penelitian ini adalah merancang destination branding Desa Wisata Ketenger dengan media-media yang informatif serta menarik dengan harapan Desa Wisata Ketenger dapat menarik wisatawan untuk lebih mengenal dan berkunjung kesana. Subjek Penelitian antara lain penggagas pertama Desa Wisata Ketenger yaitu Darsono dan Ketua POKDARWIS yaitu Ari yang juga sebagai pendiri Ketenger Adventure. Wawancara dilakukan dengan menemui subjek penelitian tersebut sehingga dapat memberikan data penting terkait sejarah desa wisata maupun sejauh mana promosi telah dilakukan. Penelitian dilakukan di Rumah Darsono dan Kantor Pokdarwis yang keduanya berada di Desa Wisata Ketenger.

Dokumentasi dilakukan melalui pengambilan gambar beberapa material promosi yang sudah rusak maupun yang perlu diperbaharui, selain itu juga untuk mengabadikan beberapa foto obyek wisata untuk dijadikan sebagai bahan promosi nantinya. Studi literatur dilakukan dengan mencari sumber data untuk menunjang data lapangan yang belum ditemukan saat melakukan wawancara, dokumentasi, maupun observasi. Studi literatur dilakukan dengan mencari sumber data dari buku, jurnal maupun media internet.

Penelitian kualitatif digunakan sebagai metode pada penelitian ini. Metode kualitatif yang digunakan menggunakan pendekatan unit analisis SWOT (Strength,Weakness, Opportunity, dan Threat) (Rangkuti,2015:18-20). Metode SWOT digunakan untuk mengetahui apa kekuatan, kelemahan, kesempatan, dan ancaman yang terdapat pada Desa Wisata Ketenger sebagai objek wisata sehingga dapat membentuk suatu perancangan komunikasi visual yang informatif sekaligus efektif untuk menjangkau masyarakat, selain itu juga efektif dalam menyampaikan 
tujuan dan pesan yang diinginkan dengan tepat dalam perancangan destination branding ini.

\section{HASIL DAN DISKUSI}

Desa Wisata Ketenger merupakan salah satu objek wisata alam yang dimiliki oleh Kabupaten Banyumas. Lokasinya masuk kedalam wilayah kecamatan Baturraden dengan luas wilayah 138.344 Ha dan terdiri dari 3 Dusun, 5 RW dan 26 RT. Desa Ketenger berbatasan langsung dengan hutan lindung Gunung Slamet pada bagian utara, desa Kutaliman kecamatan Kedung Banteng pada bagian barat, desa Karang Tengah pada bagian selatan, dan desa Karangmangu di bagian timur. Lokasinya yang berdekatan dengan Loka Wisata Baturraden menjadikan Desa Wisata Ketenger sebagai destinasi pendukung yang berfungsi sebagai penopang kegiatan pariwisata yang ada di lokasi wisata utama Baturaden. Berada di lereng Gunung Slamet menjadikan Desa wisata Ketenger memiliki cuaca yang cukup sejuk dengan potensi alam yang indah.

Di dalam Desa Wisata Ketenger sebenarnya sudah ada beberapa media promosi dan sign system, akan tetapi kondisi sangat memprihatinkan karena tidak terawat dan beberapa sudah rusak. Pada saat memasuki Desa Wisata Ketenger terlihat adanya gapura yang sudah berkarat dan kusam termakan usia. Desain gapura Desa Wisata Ketenger terlihat tidak eye catching, ditambah lagi letaknya yang sedikit menjorok ke dalam membuat gapura ini kurang bisa terlihat oleh pengunjung. Adanya peta lokasi wisata yang berada di sana pun sudah sangat tidak layak karena gambarnya sudah pudar dan rusak, besi penyangga pun sudah miring dan berkarat bahkan nyaris roboh. Sign sistem atau petunjuk arah di dalam obyek wisata memiliki desain yang kurang menarik, tidak seragam, dan tidak terlihat jika di malam hari. 
Tabel 1. Analisis SWOT Desa Wisata Ketenger

\begin{tabular}{|c|c|}
\hline \multicolumn{2}{|r|}{ Analisis SWOT Desa Wisata Ketenger } \\
\hline STRENGHT & $\begin{array}{l}\text { - } \quad \text { Suasana yang tenang dengan nuansa tradisional dan memiliki } \\
\text { pemandangan yang indah. } \\
\text { - } \quad \text { Udara yang masih segar dan minim polusi kendaraan bermotor. } \\
\text { - } \quad \text { Untuk desa, fasilitas yang ada sudah mencukupi seperti sinyal } \\
\text { telepon seluler dan beberapa sarana pendukung seperti kedai } \\
\text { yang menjual makanan dan terminal bus. } \\
\text { - } \quad \text { Terdapat beberapa tujuan wisata baik buatan maupun alam. } \\
\text { - } \quad \text { Biaya hidup bagi wisatawan masih sangat terjangkau. }\end{array}$ \\
\hline WEAKNESS & $\begin{array}{l}\text { - } \quad \text { Beberapa akses jalan menuju Desa Wisata Ketenger masih kurang } \\
\text { mendapat perhatian sehingga sering rusak. } \\
\text { - } \quad \text { Papan informasi mengenai keberadaan Desa Wisata Ketenger } \\
\text { masih sangat minim. } \\
\text { - } \quad \text { Belum adanya usaha promosi dan pembentukan branding di Desa } \\
\text { Wisata Ketenger } \\
\text { - Kurangnya akomodasi penginapan yang memadai. } \\
\text { - } \quad \text { Kurangnya perhatian dari pemerintah khususnya dari Kepala Desa } \\
\text { dalam hal pendanaan maupun pengelolaan. }\end{array}$ \\
\hline OPPORTUNITY & $\begin{array}{ll} & \text { Banyak wisatawan yang membutuhkan referensi wisata baru } \\
\text { - } & \text { Akses lokasi yang terletak tidak jauh dari jalur provinsi } \\
\text { - } \quad \text { Unit kegiatan masyarakat yang terus bermunculan }\end{array}$ \\
\hline THREAT & $\begin{array}{l}\text { - Merupakan tempat yang kurang dikenal sehingga belum } \\
\text { mendapat sorotan oleh wisatawan yang berkunjung ke Banyumas } \\
\text { - Munculnya obyek wisata buatan di lingkungan Desa Wisata } \\
\text { Ketenger yang dimiliki oleh sektor swasta. }\end{array}$ \\
\hline
\end{tabular}

Sumber : Kusuma, 2018

\section{Konsep Kreatif Perancangan}

Langkah awal yang dilakukan dalam pembuatan destination branding di Desa Wisata Ketenger ini adalah membuat konsep kreatif untuk mendasari perancangan. Penentuan positioning Desa Wisata Ketenger penting untuk diuraikan terlebih dahulu yaitu sebuah desa di bawah kaki gunung Slamet yang memiliki udara sejuk dan memiliki banyak wisata alam di dalamnya. Kemudian Desa Wisata Ketenger memiliki pula unique selling preposition yaitu banyak air terjun/curug yang berada di kawasan desa tersebut.

Konsep kreatif perancangan disesuaikan pula dengan target audience yang ingin digaet agar mengunjungi Desa Wisata Ketenger. Target audience primer memiliki segmentasi geografis dari seluruh Indonesia dan luar negeri. Segmentasi 
Monica Revias Purwa Kusuma dan Elianna Gerda Pertiwi PERANCANGAN DESTINATION BRANDING DESA WISATA KETENGER KABUPATEN BANYUMAS UNTUK MENDUKUNG PROGRAM DIGITAL DESTINATION.

Demografisnya yaitu berjenis kelamin laki-laki maupun perempuan yang memiliki rentang usia 13-50 tahun, memiliki pendidikan SMP sampai dengan perguruan tinggi, serta memiliki status sosial menengah sampai dengan menengah keatas. Segmentasi Psikografisnya yaitu masyarakat yang bosan dengan pariwisata utama di Baturraden dan ingin mencari alternatif pariwisata lain ketika sedang berada di Banyumas dan sekitarnya.

Media-media yang digunakan untuk mendukung destination branding Desa Wisata Ketenger juga disesuaikan dengan segmentasi target audience. Oleh karena itu gaya desain dan karakteristik visual akan menonjolkan manfaat emosional yang mencerminkan diri target audience melalui perancanganperancangan kreatif yang berbentuk verbal dan visual. Verbal menyangkut isi pesan berupa ungkapan bahasa yang berfungsi untuk mempermudah mengingat di benak target audience. Di dalam pesan verbal ini nantinya akan ada slogan atau tagline yang selalu digunakan di hampir semua media promosi. Selanjutnya adanya aspek visual yang terdiri dari visualisasi ilustrasi, visualisasi tipografi, dan warna. Visualisasi ilustrasi yang digunakan adalah dengan menggunakan foto. Foto digunakan agar memudahkan target audience untuk membayangkan bagaimana keindaan obyek wisata yang ada di Desa Wisata Ketenger. Visualisasi tipografi yang akan digunakan nantinya yaitu menggunakan jenis huruf yaitu san serif agar terlihat santai dan tidak kaku. Warna yang digunakan adalah warnawarna netral seperti hitam, abu-abu, cokelat, serta satu warna mencolok yaitu kuning agar menjadi pusat perhatian.

Gaya desain juga digunakan untuk memunculkan karakter visual yang memiliki keterikatan satu sama lainnya sehingga mudah dikenali sebagai salah satu media promosi desa wisata tersebut. Gaya desain yang akan digunakan untuk perancangan ini terinspirasi gaya desain Early Modern yang memiliki bentuk geometrikal, minimalis, clean, dan lebih menekankan penggunaan foto dengan sedikit ilustrasi. 


\section{Standard Visual}

Standard visual dalam sebuah perancangan berfungsi sebagai acuan dari desain-desain dan item-item yang dibuat. Dalam Perancangan Destination Branding Desa Wisata Ketenger ini meliputi pesan verbal dan pesan visual. Pesan verbal merupakan pesan berupa bahasa yang dirangkai dalam bentuk kalimat. Pesan verbal sangat penting peranannya, selain menginformasikan pesan, juga sebagai salah satu unsur grafis yang sangat berpengaruh pada saat membuat layout.

Pesan verbal dalam perancangan ini yaitu slogan yang akan selalu ada disetiap media promosi berdampingan dengan logotype Desa Ketenger yaitu 'Hidden Paradise in Purwokerto'. Kata-kata tersebut dipilih walaupun Desa Ketenger sendiri tepatnya berada di Kabupaten Banyumas bukan di Purwokerto. Purwokerto sendiri memang sengaja dipilih karena Purwokerto merupakan ibukota Kabupaten Banyumas dan lebih familiar dikenal oleh warga Indonesia pada umumnya. Pada perancangan ini body copy yang akan disampaikan yaitu nama-nama tempat pariwisata unggulan yang ada di Desa Wisata Ketenger, diharapkan saat membaca body copy tersebut target audience menjadi paham apa saja pariwisata yang ditawarkan di Desa Wisata Ketenger tersebut.

Pesan visual dalam perancangan ini menggunakan ilustrasi yang menggunakan foto dan dipadu padankan dengan olah digital untuk membentuk framing yang lebih luwes. Sedangkan ilustrasi pendamping menggunakan gambar vektor seperti yang dibuat pada peta Desa Wisata Ketenger. Pada perancangan destination branding Desa Wisata Ketenger ini menggunakan tipografi dengan jenis san serif karena simpel dan memiliki keterbacaan yang mudah. Jenis-jenis font yang digunakan yaitu Sharkboy \& Lavagirl, Source San Pro Semi Bold, Century Gothic, Calibri Light. Warna yang akan digunakan dalam perancangan menggunakan warna-warna netral seperti warna tanah (coklat) dan warna air (biru), putih, hitam, abu-abu serta tambahan warna untuk membuat point of 
Monica Revias Purwa Kusuma dan Elianna Gerda Pertiwi PERANCANGAN DESTINATION BRANDING DESA WISATA KETENGER KABUPATEN BANYUMAS UNTUK MENDUKUNG PROGRAM DIGITAL DESTINATION.

interest bagi yang melihat seperti warna kuning. Layout dalam desain perancangan destination branding Desa Wisata Ketenger adalah menggunakan jenis layout jumble yaitu komposisi berupa gambar dan tulisan yang teratur.

\section{Aplikasi Desain}

Logo ditempatkan pada seluruh media promosi yang dibuat pada perancangan. Logo yang dibuat terinspirasi dari banyaknya air terjun di Desa Wisata Ketenger serta letak Desa Wisata tersebut yang berada di kaki Gunung Slamet.
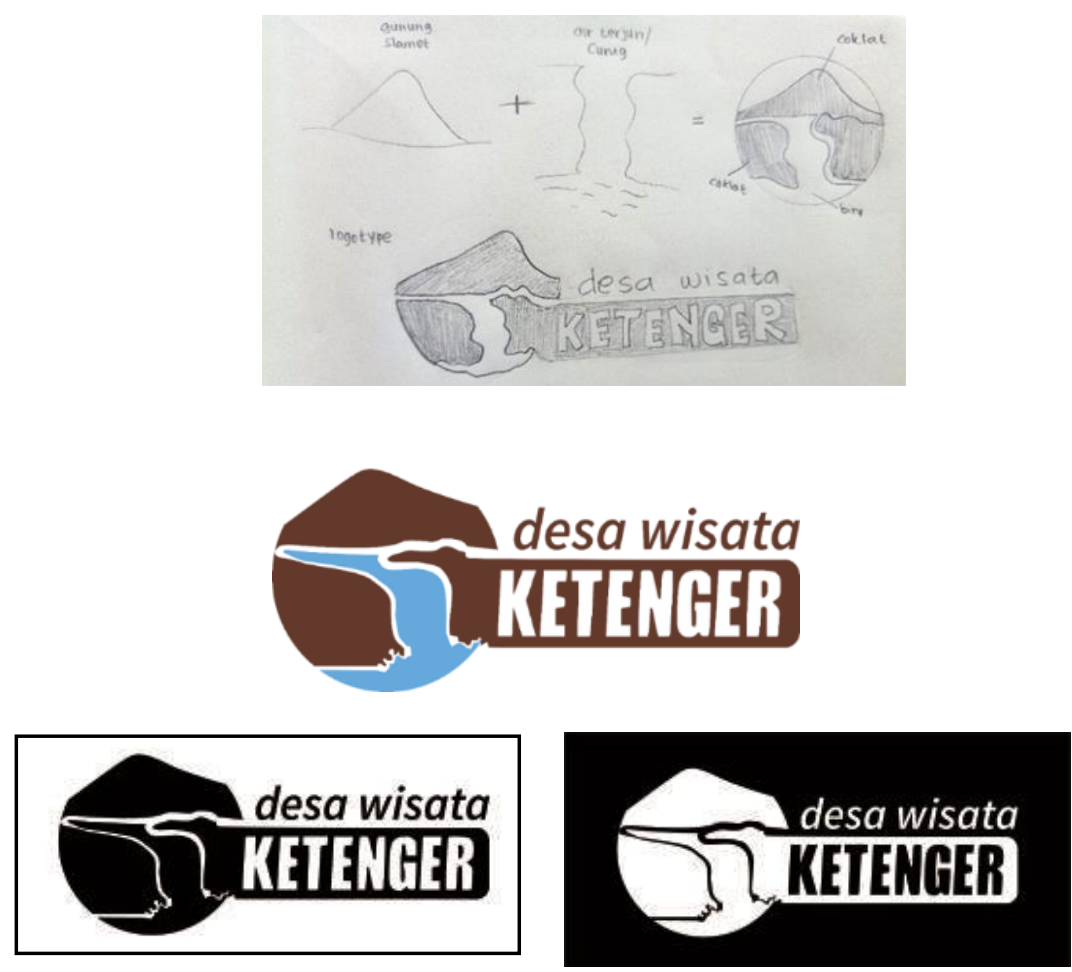

Gambar 2. Perancangan Logo Desa Wisata Ketenger Full Color \& B/W Sumber : Kusuma, 2018 


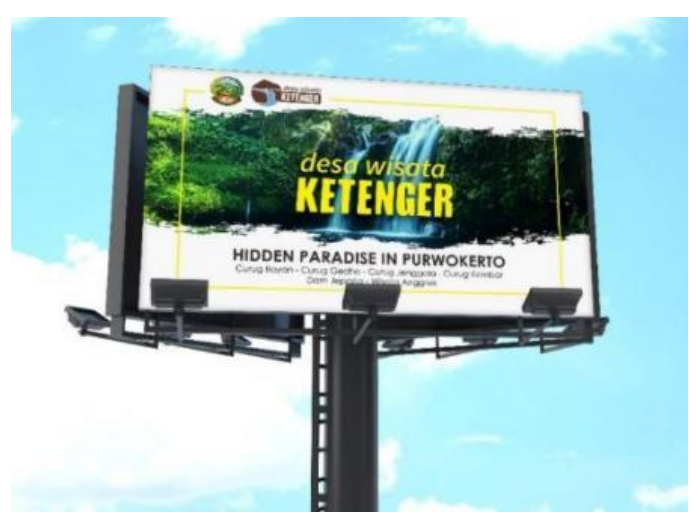

Gambar 3. Perancangan Billboard Desa Wisata Ketenger

Sumber : Kusuma, 2018

Billboard merupakan Above the Line media yang ditempatkan di pinggir jalan raya (dekat lampu merah) di Purwokerto maupun dekat Desa Wisata Ketenger (Gambar 3). Spanduk Jalan merupakan Above the Line media yang ditempatkan di jalan-jalan masuk menuju Desa Wisata Ketenger atau menuju obyek-obyek di dalamnya (Gambar 4).
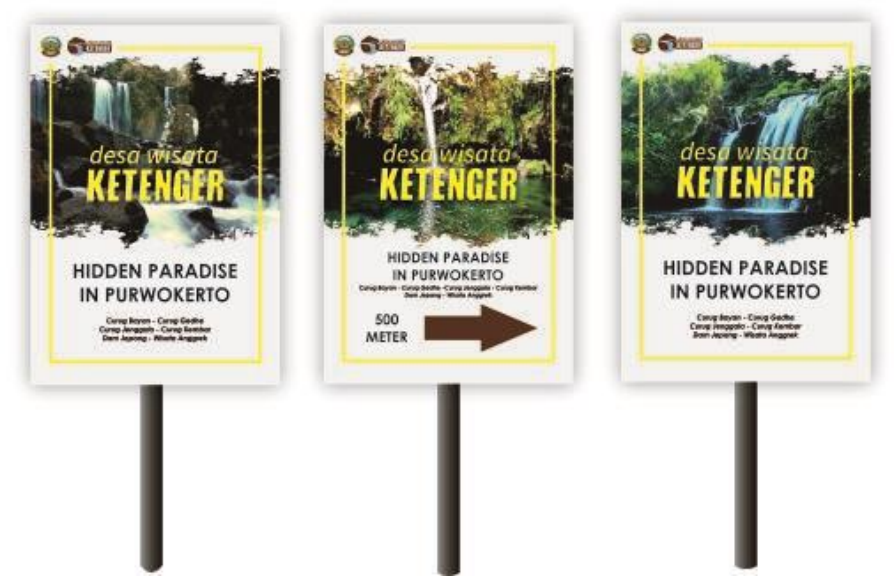

Gambar 4. Spanduk Jalan

Sumber : Kusuma, 2018

Brosur merupakan Below the Line media yang ditempatkan di pusat informasi Desa Wisata Ketenger dan di loket-loket tiket masuk pariwisata (Gambar 5). 


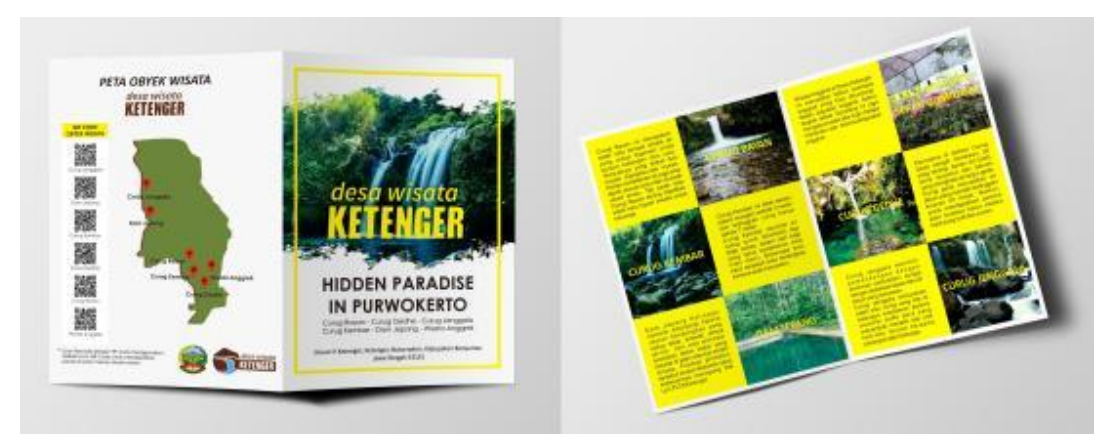

Gambar 5. Desain Brosur Desa Wisata Ketenger

Sumber : Kusuma, 2018

Karcis Masuk Wisata merupakan Below the Line media yang digunakan di loket-loket tiket masuk pariwisata (Gambar 6).
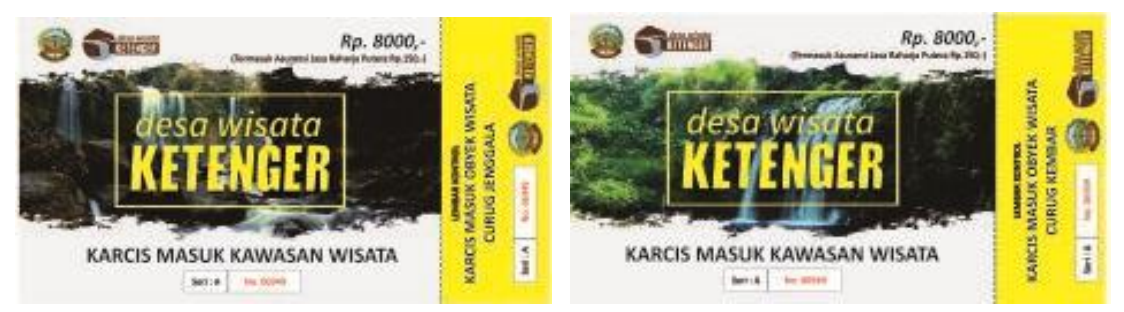

Gambar 6. Desain Karcis Masuk Desa Wisata Ketenger

Sumber : Kusuma, 2018

Instagram diformat dengan desain artistik untuk meng-update post di Instagram agar lebih rapi sekaligus estetis sehingga mudah menarik minat follower untuk mengunjungi Desa Wisata Ketenger (Gambar 7). 


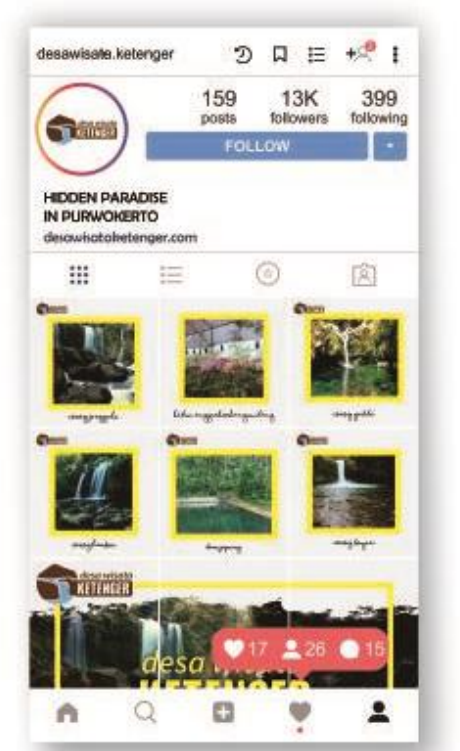

Gambar 7. Desain untuk update post di Instagram Desa Wisata Ketenger Sumber : Kusuma, 2018

Mobil Branding merupakan Below the Line media yang dipakai untuk mobil dinas para pejabat pemerintah/ perangkat Desa Wisata Ketenger (Gambar 8).

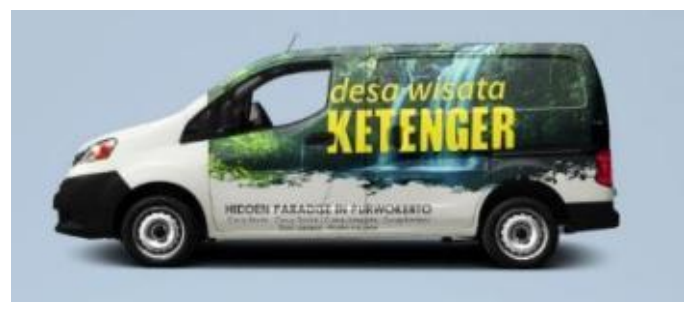

Gambar 8. Desain Mobil Branding Desa Wisata Ketenger Sumber : Kusuma, 2018

Kaos dijual sebagai oleh-oleh atau sebagai merchandise di obyek-obyek wisata Desa Wisata Ketenger (Gambar 9). 


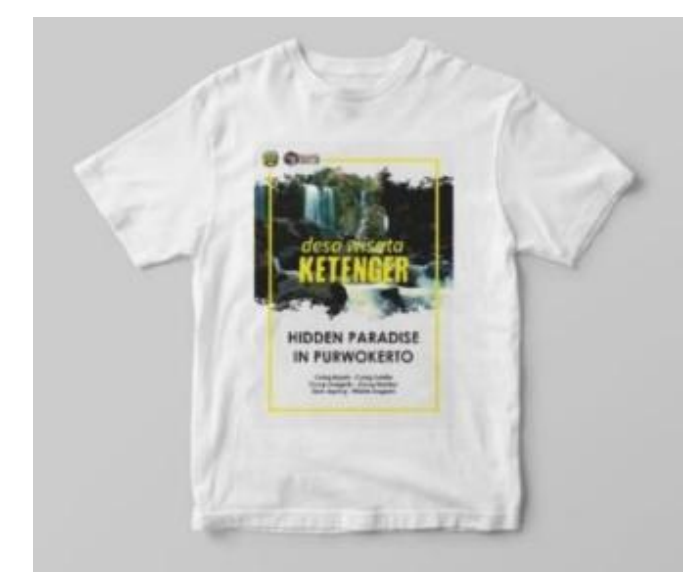

Gambar 9. Desain Kaos Desa Wisata Ketenger Sumber : Kusuma, 2018

Gapura Desa Wisata ditempatkan di gerbang masuk Desa Wisata Ketenger (Gambar 10). Bahan logo dan tulisan 'Selamat Datang' dibuat dari bahan lampu neonbox yang menyala pada malam hari. Pada bagian bawahnya tulisan obyek wisata dibuat dari akrilik yang menyala pada malam hari karena dilapisi dengan fosfor.

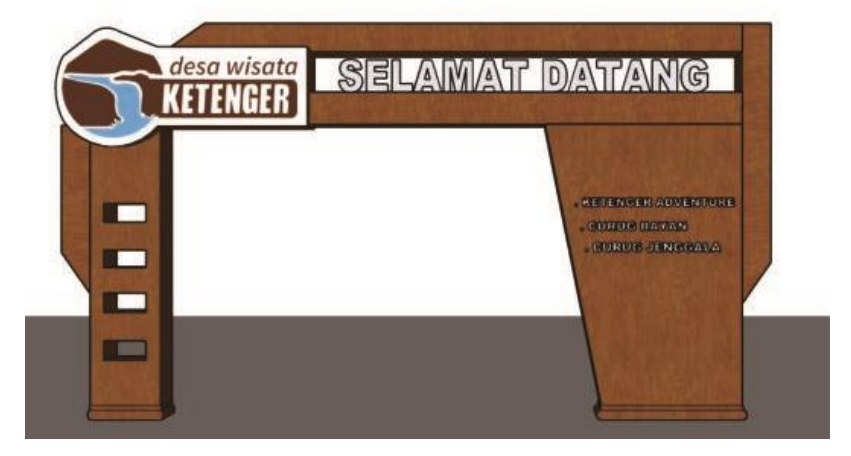

Gambar 10. Desain Gapura Desa Wisata Ketenger Sumber : Pertiwi, 2018

Sign System Peta Wisata dan Arah Tempat ditempatkan di dekat gerbang masuk Desa Wisata Ketenger, di luar atau di dalam obyek wisata. 

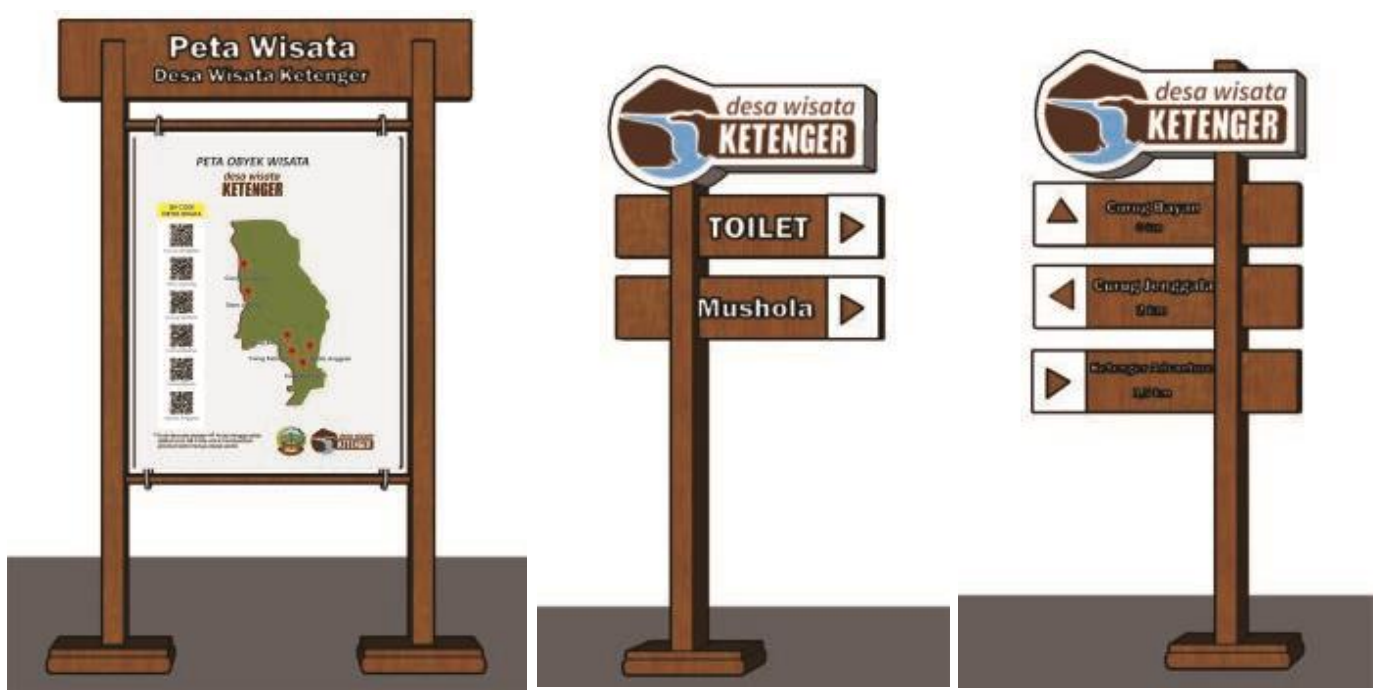

Gambar 11. Desain Sign System Peta Wisata \& Arah Desa Wisata Ketenger Sumber : Pertiwi, 2018

Sign System informasi Tempat Wisata ditempatkan di gerbang masuk tiaptiap obyek wisata di Desa Wisata Ketenger(Gambar 12).

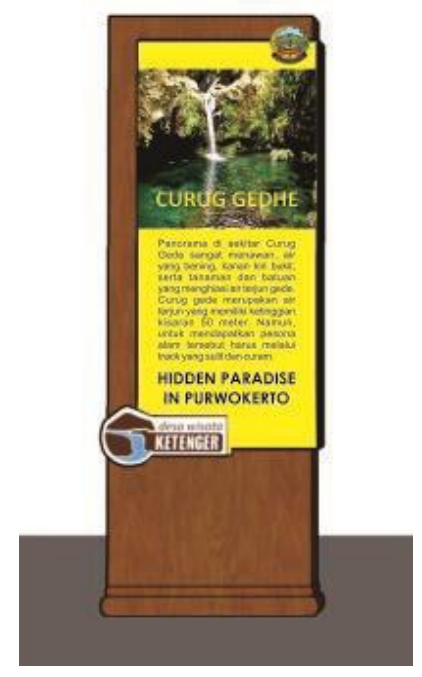

Gambar 12. Desain Sign System Informasi Tempat Wisata Desa Wisata Ketenger Sumber : Pertiwi, 2018

Spot Foto Instagrammable (Gambar 13) ditempatkan di dalam obyek-obyek wisata Desa Wisata Ketenger disesuaikan dengan kontur 
Monica Revias Purwa Kusuma dan Elianna Gerda Pertiwi PERANCANGAN DESTINATION BRANDING DESA WISATA KETENGER KABUPATEN BANYUMAS UNTUK MENDUKUNG PROGRAM DIGITAL DESTINATION.

alamnya. Spot foto ini salah satunya ada yang bernama tugu corat-coret yaitu untuk mewadahi keisengan para traveler dalam mencorat-coret agar tidak merusak kebersihan alam sekitar.

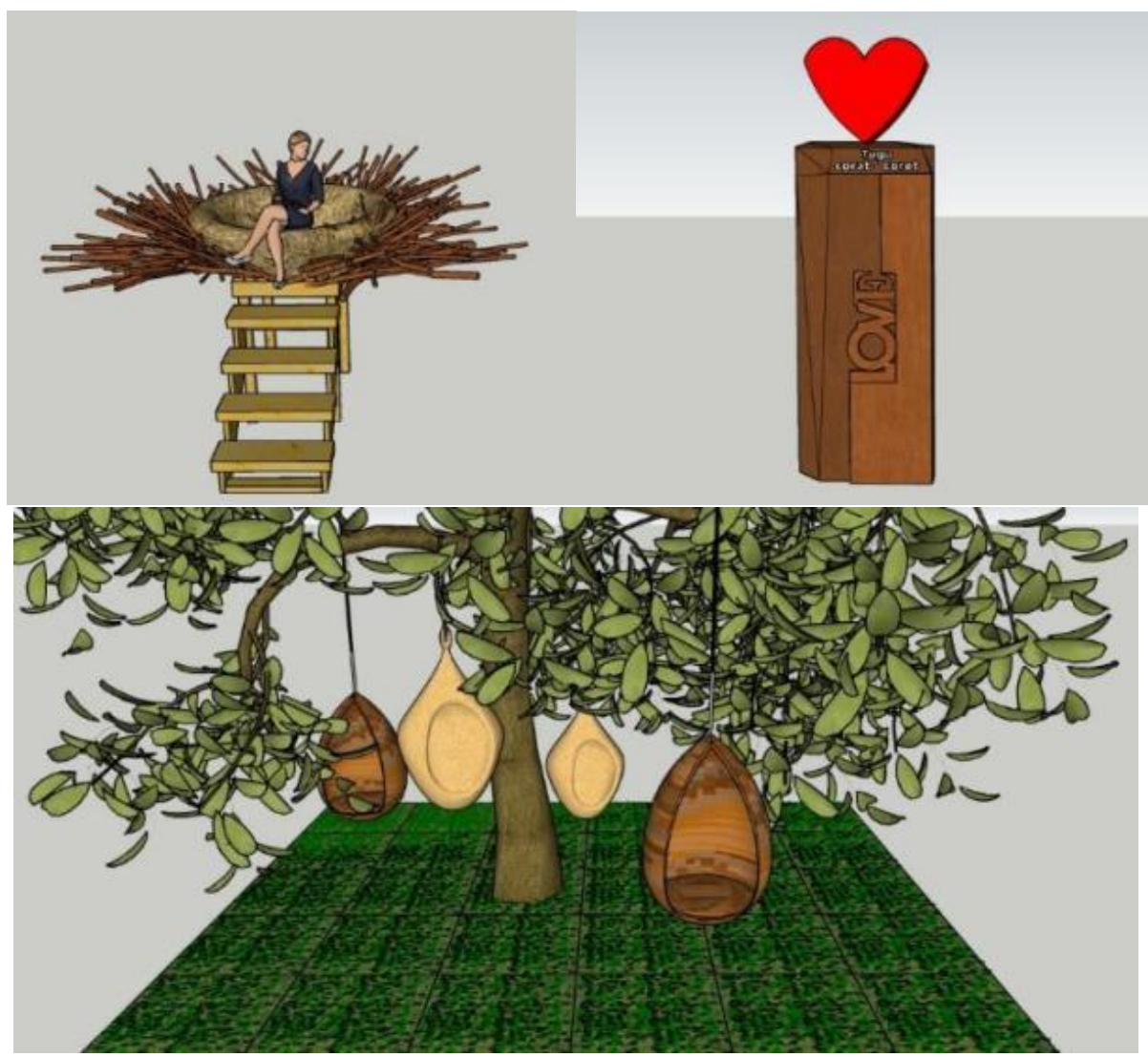

Gambar 13. Tiga Desain Spot Foto di Desa Wisata Ketenger

Sumber : Pertiwi, 2018

\section{Program Media}

Tujuan media pada hakekatnya ditentukan dengan cara menentukan jangkauan, frekuensi, kesinambungan media. Jangkauan media yang diharapkan dalam perancangan destination branding Desa Wisata Ketenger adalah media yang dapat mencapai target audience wisatawan yang berumur $13-50$ tahun. Tujuan media yang diharapkan adalah mencapai tujuan perancangan berupa promosi yang sesuai dengan perancangan yang telah dibuat dan minimal dapat 
menjangkau target audience sewaktu promosi dilakukan yaitu minimal $75 \%$ dari sasaran.

Frekuensi yang diharapkan adalah media dengan frekuensi kemunculan yang dapat menarik perhatian target audience yang berdomisili di luar Kabupaten Banyumas. Tujuan media yang diharapkan adalah dapat mencapai tujuan perancangan sesuai perencanaan secara serentak dan menyeluruh. Iklan akan dilakukan selama 1 tahun dengan berbagai media yang disesuaikan.

Kesinambungan informasi tentang Desa Wisata Ketenger akan tetap terjaga melalui media promosi yang telah dibuat seperti billboard, brosur, spanduk jalan, update instagram, dan sign system.

\section{KESIMPULAN}

Perancangan destination branding Desa Wisata Ketenger Kabupaten Banyumas dibuat untuk mendukung program pemerintah yaitu digital destination dengan mendesain spot-spot fotogenik agar dapat diviralkan oleh para wisatawan, sehingga Desa Wisata Ketenger lebih dikenal. Adanya spot-spot fotogenik tersebut memberikan kesan emosional tersendiri bagi para wisatawan yang berkunjung kesana. Selain spot-spot fotogenik dibuat pula identitas visual Desa Wisata Ketenger yang dituangkan dalam bentuk logo yang terinspirasi bentuk gunung dan air terjun. Media promosi lain juga dibuat untuk mendukung perancangan destinasi branding terasa lebih nyata yaitu dari above the line media yang berupa billboard, brosur, spanduk jalan, dan juga postingan iklan di Instagram. Below the line media juga dibuat untuk mendukung promosi yaitu kaos, tiket masuk, dan branding stiker pada mobil. Untuk mendukung destination branding yang berkesinambungan, pada gapura pintu masuk dan sign system di semua obyek wisata yang didesain memiliki kesamaan bahan agar terlihat seragam.

Dengan adanya perancangan destination branding Desa Wisata Ketenger ini diharapkan dapat meningkatkan wisatawan untuk datang dan berkunjung ke sana 
Monica Revias Purwa Kusuma dan Elianna Gerda Pertiwi PERANCANGAN DESTINATION BRANDING DESA WISATA KETENGER KABUPATEN BANYUMAS UNTUK MENDUKUNG PROGRAM DIGITAL DESTINATION.

sehingga menambah pendapatan desa wisata tersebut. Perancangan ini diharapkan juga memberikan dampak positif kepada masyarakat agar lebih melek terhadap potensi pariwisata di daerahnya untuk mengolah sektor pariwisata yang ada. Semoga dengan perancangan ini bisa membuka jalan agar Desa Wisata Ketenger bisa berkembang menjadi suatu Desa Wisata yang dapat diperhitungkan baik di tingkat Nasional maupun Internasional.

\section{PERNYATAAN PENGHARGAAN}

Terimakasih penulis ucapkan kepada LPPM Institut Teknologi Telkom Purwokerto sebagai penyokong dana dari penelitian internal ini.

\section{DAFTAR PUSTAKA}

Anholt, Simon, 2009. Handbook on Tourism Destination Branding. New York: World Tourism Organization Pubn.

Baker, M.J.,Cameron, E., 2008. Critical Success Factors in Destination Marketing, Tourism and Hospitaly Research Journal Vol 8 Issue 2, 79-97

Darmastuti, Rini, 2012. Media Relations : Konsep, Strategi dan Aplikasi. Yogyakarta : Penerbit ANDI.

Prafitri, G.R., Maya, D., 2016. Kapasitas Kelembagaan Desa Wisata (Studi Kasus : Desa Wisata Ketenger, Banyumas), Jurnal Pengembangan Kota Vol 4 No 1, 76-86).

Rangkuti, Freddy, 2009. The Power of Brands Teknik Mengelola Brand Equity dan Strategi Pengembangan Merek plus Analisis Kasus dengan SPPS Edisi 4. Jakarta : PT. Gramedia Pustaka Utama.

Tinarbuko, Sumbo, 2015. DEKAVE Desain Komunikasi Visual - Penanda Zaman Masyarakat Global. Yogyakata : CAPS 
Wheeler, Alina, 2013. Designing Brand Identity:an Essential Guide for the Whole Branding Team, 4th Edition. Hoboken, New Jersey : John Wiley \& Sons, Inc. Larasati, Ekasari, 2018. Kenali Berbagai Aliran Dalam Desain Grafis. Jakarta : IDS Design School. Tersedia di <https://idseducation.com/articles/kenaliberbagai-aliran-dalam-desain-grafis/ > [18-11-2018, 19:50 WIB] 